\title{
De Regímenes de historicidad a Chronos. Una historia del tiempo en Occidente
}

\author{
г \\ From Regimes of Historicity to Chronos. \\ A History of Time in the West
}

\author{
Norma Durán R.A. \\ Universidad Autónoma Metropolitana-Azcapotzalco \\ México \\ Correo: norma.duran03@gmail.com \\ DOI: 10.48102/hyg.vi57.39|
}

Reseña recibida: 19/01/2021

Reseńa aceptada: 01/03/2021

Hartog, François. Chronos. L’Occident aux prises avec le Temps, París, Gallimard, 2020, 344 pp.

Cronos. Occidente frente al tiempo, sería más o menos la traducción del título del último libro de François Hartog que acaba de salir en octubre del turbulento 2020, publicado por la acreditada editorial Gallimard. Es un libro de sólida madurez intelectual que refleja los años de trabajo y reflexión de uno de los grandes historiadores franceses de los últimos veinte años del siglo xx y de los primeros del xxi. También en este 2020 se cumplen cuarenta años de su primera gran obra: El espejo de Heródoto, producido también por las prensas de Gallimard.

Podemos decir que si la indagación sobre el tiempo comenzó formalmente con Regimenes de historicidad, publicado en 2003, ${ }^{1}$

${ }^{1}$ Después de esta obra, François Hartog ha publicado en la Universidad Iberoamericana: Evidencia de la historia, (2011); y De los antiguos a los modernos, de los modernos a los salvajes. Para una historia intelectual de Europa (2015).

Historia y Grafia, Universidad Iberoamericana, año 29, núm. 57, julio-diciembre 2021, pp. 333-349 
Cronos completa su reflexión acerca del tema. En aquel libro introdujo la fórmula, "regímenes de historicidad", que muy pronto fue de uso común entre historiadores y todo tipo de investigadores de ciencias humanas. Lo formuló, no como un concepto, sino como instrumento heurístico para poder describir las formas de articular el tiempo, pero también, de la manera de reflejarlo en la escritura de la historia. El tiempo de la Modernidad, aquel que comenzó a cambiar a fines del siglo xviII y que perduró por casi dos centurias con la bandera de que todo futuro sería mejor, ya no era evidente. El siglo XIX y gran parte del xx vivieron concibiendo el futuro como faro iluminador. Si la Antigüedad, la Edad Media y la primera Modernidad habían encontrado en el pasado su referencia y guía (con múltiples variantes), ya para concluir el XVIII se comenzó a invertir la fórmula. De mano de la ciencia se aceleraba el tiempo, se vislumbraba un futuro venturoso y abierto. Esto se refleja en el optimismo en el porvenir y en la seguridad europea como la cultura de vanguardia. Se sabía hacia dónde ir y qué historia construir: las historias nacionales son fruto de este régimen de historicidad, que buscaba en lo mejor de sus pasados el origen del comienzo de la nación. Es este régimen el que fue perdiendo su evidencia. Primero, ante la hecatombe de las dos guerras mundiales $\mathrm{y}$, aunque todavía pudo sostenerse en las décadas siguientes, en los setenta y los ochenta se fue disipando el triunfalismo del siglo XIX.

Regimenes de historicidad indagaba sobre las fisuras que se iban reflejando en el tiempo de la Modernidad; en él hacía el diagnóstico de lo que denominó "presentismo", es decir, la articulación temporal en donde dominaba un presente continuo, un tiempo en el que la aceleración era la característica. El presentismo, apremiado por los medios de comunicación, se volvía lo sintomático. Esto lo puede detectar contrastando formas pasadas de vivir y de concebir el tiempo. Hartog volvía a recorrer periodos de la historia de Grecia al presente encontrando diferencias, signos, señales, indicios a finales de la década final del siglo. Así diag- 
nosticó y denominó como "presentismo" a esa nueva articulación donde el presente era el tiempo predominante. El futuro ya no se veía esperanzador, el pasado se desvanecía ante cada presente y lo que comenzaba a prevalecer era éste. Memoria, patrimonio, conmemoración, identidad, fueron los signos de ese "presentismo". También se vivía como un pasado que no acababa por pasar y que afloraba en la voz del testimonio de quienes ya no podían darlo: los recuerdos de los sobrevivientes de los muertos del Holocausto y de las guerras hicieron que la memoria compitiera con la historia, hasta que la historia logró atraparla y volverla su objeto de estudio.

La manera de trabajar de Hartog es muy particular y no todos los historiadores pueden realizarla, pues enfrascados éstos en sus nichos o periodos de estudios es muy difícil (por las competencias y la erudición que cada lapso exige) ir y venir entre etapas, culturas y sociedades diferentes. Gran lector de teoría de la historia, de filosofía y de literatura, Hartog se ha impuesto siempre a hablar desde la historia, haciendo lo que, desde la sociología de Niklas Luhmann, implicaría el cierre operativo de la disciplina: la historia desde la historia. Pero sin ingenuidad, siempre la teoría está detrás. Reivindica con gusto aquel aserto de Koselleck, quien, en palabras de José Luis Villacañas, pensaba que "sin teoría no es posible la investigación histórica”. ${ }^{2}$ Con su estilo recurrente, su ir y venir entre pasado, presente y futuro, articulados, desde Koselleck como "campo de experiencia" y "horizonte de expectativas", pudo nombrar ese presentismo como manera de sentir y estar en el tiempo, lo que también se vio reflejado en la escritura de la historia. A esa obra pionera, trabajo de dictamen, le siguieron otras en las que indagó más temáticas que interrogaban el tiempo y la historia; sin embargo, es Cronos la que completa su reflexión sobre el tiempo.

\footnotetext{
${ }^{2}$ Reinhart Koselleck, Esbozos teóricos. ¿Sigue teniendo utilidad la historia?, intr. de José Luis Villacañas, Madrid, Escolar y Mayo Editores, 2010, p. 10.
} 
Como he dicho, Cronos es una obra de madurez intelectual. La presenta como un ensayo de historia conceptual. La lectura del libro de Reinhart Koselleck, Futuro pasado, traducido al francés en 1990 y, que coincidió con la estancia de un año de Hartog en Berlín, le proporcionaron las herramientas interpretativas para profundizar en el problema del tiempo; sin embargo, él ya se había topado con el tema debido a su gusto por la antropología, ${ }^{3}$ que le hacía patente temporalidades e historicidades diferentes. El libro de Koselleck, por su parte, era un conjunto de artículos de entre 1960 y 1970, en donde aparecían estas dos categorías que, el historiador alemán, utilizaba para destacar el orden del tiempo que la Modernidad introducía (a finales del siglo XviII) y de donde surgía el colectivo singular de historia que dominó de ahí en adelante. La preocupación de Koselleck obviamente no era el presente de fines de siglo XX. ${ }^{4}$ Su preocupación era intuir el "horizonte de expectativas" de la Alemania de posguerras. La introducción de la semántica histórica le permitía profundizar en el tema del tiempo.

Cronos está dividido en seis capítulos y abarca de los griegos a la actualidad. Los primeros cuatro los dedica a la construcción del tiempo cristiano. Lo propio del tiempo es, nos dice, su inasibilidad. Desde los griegos, el hombre se ha empeñado en cazar

${ }^{3}$ En una reseña sobre el libro de Marshall Sahlins de 1983, Islas de historia. La muerte del capitán Cook. Metáfora, antropología e historia, Barcelona, Gedisa, 1997, Hartog, elabora el sintagma "regímenes de historicidad". Diez años después, convergiendo con su lectura de obras de antropología, y con el antropólogo Gérard Lenclud, lo redefine. Cfr. François Hartog, La cámara de guardia, México, Editorial Navarra, 2020, pp. 118 ss.

Remito al lector a este último libro que he traducido de él. Obra indispensable para entender su camino intelectual, sus intereses, sus lecturas, los maestros que lo marcaron, sus experiencias de juventud, su fascinación por la navegación, cómo va avanzando en sus reflexiones, su forma de trabajar, el porqué se inclinó por la historia antigua, como una especie de refugio, para reflexionar sobre su presente, el de 1968, momento que su generación no había sabido o no pudo entender. La decisión de dedicarse a la historia antigua equivale, en palabras que pide prestadas a Lévi-Strauss, a dar un paso de lado y distanciarse para ver desde más lejos, siempre, para iluminar el presente.

${ }^{4}$ Cfr. Ibidem, p. 121. 
a éste, medirlo, domarlo, domesticarlo... sin fructificar. Se "está en el tiempo", 5 y por ello se han inventado términos para hablar de él, se han creado desdoblamientos, binomios, como lo hizo san Agustín oponiendo tiempo a infinitud; pero mucho antes, los griegos movilizaron otros operadores como Cronos, Kairos y Krisis. Si Cronos es el tiempo ordinario, el tiempo del movimiento de los astros, sus ciclos, sus "revoluciones", que es el sentido original de esta palabra, Kairos es el instante crucial, "una ruptura en la continuidad espacial y temporal, una discontinuidad en la continuidad, también [un cambio en] calidad de tiempo con respecto a cantidad de cronos" (pp. 22 ss.). Krisis, el tercer concepto operativo de los griegos, significaba, en un primer momento, juicio; provenía del ámbito judicial, pero también aparece en el campo médico hipocrático, donde indica el momento determinante en que la enfermedad o cedía o empeoraba indefectiblemente. La medicina griega combinaba estos tres términos en el diagnóstico y curación del enfermo. Es por demás decir que ellos no tenían un sentido ni una significación estable. Por otro lado, Hartog también nos ofrece sus etimologías y significados míticos.

Un momento clave fue la traducción, al griego, del Pentateuco en el siglo ini a. de C., ya que es el momento cuando estos términos penetran en otra cultura y son reformulados, pues deben acomodarse para dar cuenta de otro mundo muy diferente del griego. En la traducción de los Setenta o Septuaginta, Cronos, Kairos y Krisis se introducen en un mundo muy diferente al griego. Esta traducción tenía como finalidad ser utilizada por los judíos de Alejandría y formar parte de la famosa biblioteca, aunque nunca sustituyó a la Biblia en hebreo de las otras comunidades. Lo que interesa seguir de Hartog es la manera en que se introdujeron estos términos en el cristianismo surgido de las nuevas comunidades que emergieron con Jesús de Nazaret. De ahí en adelante el uso de Kairos y Krisis toma un sentido muy diferente. Con muchos

\footnotetext{
${ }^{5}$ Epígrafe que Hartog toma de Proust para Regímenes de historicidad.
} 
matices, podemos decir que Krisis se vuelve el juicio final y Kairos en el evento central del cristianismo: la Encarnación. Hartog analiza los textos centrales del cristianismo, como las epístolas paulinas, que buscan hacer comprensible, a las nuevas comunidades, cómo entender el tiempo a partir de la Encarnación; comprender el cambio del tiempo de la ley al tiempo de la fe. Es decir, el elemento central ya se produjo, ahora sólo queda esperar la vuelta del Mesías (Parusía) y el Juicio final. Pasado y futuro encuentran una nueva formulación en el tiempo cristiano. Se está ya en la Plenitud del tiempo (formulación posterior de san Agustín), que significa que se vive ya bajo la promesa cumplida, en espera del fin, no de los tiempos (esto le corresponde en exclusiva a Dios) sino del mundo; es así como lo que será, de aquí en adelante, el Viejo Testamento, se reveló tras el acontecimiento del advenimiento del Mesías, es decir, la profecía ya se cumplió. Esta manera de leer los textos es lo que se denomina lectura tipológica. Por lo tanto, siempre habrá una interpretación de los acontecimientos presentes con este tipo de lectura, que multiplican Krisis y Kairos.

Krisis y Kairos reconvierten la configuración del tiempo pues lo han cortado, dividido y reformulado de una manera completamente inédita. Lo único estable es el consenso de que el dueño absoluto de todos los tiempos es Dios. Pero el acontecimiento, la Encarnación, ha "escatologizado, apocaliptizado, mesianizado, transformado y dominado" (p. 33) a Cronos. La apelación de Iesous christos que, como nombre propio pasa como Jesús-Cristos, revela ya la introducción del elemento mesiánico: Cristo es la traducción griega de la palabra hebrea para "mesías". El mundo griego no conoció figuras apocalípticas o mesiánicas; en cambio, el mundo judeocristiano sí. El Apocalipsis de san Juan, que cierra el Nuevo Testamento, daría nombre a todo este tipo de literatura, incluso a textos anteriores, como los escritos proféticos de la $\mathrm{Bi}$ blia hebrea (pp. 42 ss.). ¿ ¿Cómo va trazando Hartog el cambio?

${ }^{6}$ El nombre de Apocalipsis para referirse a un "género" apocalíptico es tomado del Apocalipsis de Juan y será usado retrospectivamente para textos anteriores. 
Él sigue los cambios introducidos en los Evangelios, aunque sin detenerse en los debates entre los eruditos sobre la autoría de los textos. Desde el primer capítulo percibe la novedad y originalidad del régimen de historicidad cristiano.

En los capítulos siguientes, Hartog se centra en el problema de la contabilización de Cronos, es decir, en la combinación de los distintos cómputos del tiempo, tanto de las formas paganas como de las hebreas. Para estas comunidades era muy importante unificar los calendarios de las diferentes comunidades cristianas. En principio nada más eran calendarios litúrgicos para ubicar la Pascua, y los eventos de la vida de Cristo. Con la tardanza de la Parusía hubo la necesidad de tratar de contabilizar el tiempo ordinario, Cronos. Ya no era únicamente el acomodo de Krisis y Kairos sino también el tiempo de los asuntos humanos con el tiempo astral. Las comunidades monásticas inventaron el calendario litúrgico o "liturgia de las horas"; por otra parte, se había asumido la semana de siete días, proveniente de la Biblia, sólo se sustituyó el Sabbat, por el domingo, como Día del Señor, día del descanso. El nacimiento de Jesús se acordó el 25 de diciembre, día del solsticio de invierno, que reemplazaba el inicio de las saturnalias. Las demás fiestas se organizaron en torno a calendarios lunares y por lo tanto quedaron móviles. Pero ¿cómo ir más allá del tiempo litúrgico, de los ciclos lunares y solares? El pueblo hebreo tenía su propia cronología con base en la Creación y también a partir de la sucesión de imperios (con las profecías de Daniel sobre todo) y los acontecimientos, tipo Kairos, como el exilio de Babilonia, o la destrucción y reconstrucción del templo, etc.

El esfuerzo gigantesco de los matemáticos y pensadores de los primeros cinco o seis siglos se centraron en combinar los calendarios lunares con los solares, el cómputo de la creación del mundo hebreo (que sumarían en su totalidad seis mil años); más tarde se trató de adecuar con las listas dinásticas, olímpicas, arcónticas, de fundación de ciudades, etc., de los pueblos conocidos con sus acontecimientos relevantes. Del gigantesco esfuerzo de estos 
cronógrafos y padres de la Iglesia destacan las figuras de Julio el Africano y Eusebio de Cesarea. Ambos escribieron cronografías. El primero la organizó de Adán a su presente - por desgracia, de su obra sólo quedan fragmentos-; Eusebio continúa esta tradición y organiza sus tablas de Abraham a Jesús. El método de trabajar las cronologías fue consignar las fechas importantes en columnas tratando de sincronizarlas con otro tipo de eventos para ubicar la fecha del nacimiento de Cristo, de su vida pública (mencionadas de paso en los Evangelios) (Cfr. p. 118) relacionándolos con los reinados de los emperadores romanos o con los gobernadores de las provincias romanas del cercano Oriente. Estos grandes cronógrafos de los siglos III al vi establecen los eventos clave del tiempo cristiano. La elaboración de estas Tablas permitía "leer" de forma vertical la sucesión de acontecimientos relevantes y, horizontalmente mirarlos de manera simultánea. Por otra parte, la Historia eclesiástica de Eusebio establecía la historia del cristianismo como la cadena consecutiva de testigos y de testimonios, de testigos de testigos y así en lo subsecuente. Además, asumía la historia como la consignación de la cristianización de los pueblos. Vista de este modo, se concibe la historia como una historia de la salvación.

Pero ¿̇cómo tratar el tiempo pleno de la salvación, cuando pasan ya siglos y siglos sin que llegue la Parusía? El presentismo que Hartog enunció en aquella obra, Regimenes de historicidad, vuelve a aparecer, ahora para entender este eterno presente en espera de la Parusía. Pero nada tiene que ver con el presentismo moderno. Si echa mano de él es para volver asequible el modo de vivir el tiempo de los cristianos, ya que el evento clave, Kairos, ya se dio y se vive un "presentismo" que, en teoría, sólo espera ver llegar la Parusía prometida, que indica el comienzo de la verdadera vida del justo: la eternidad prometida para quien aceptó y vivió según el mensaje evangélico. Dicho de otra manera, el tiempo cristiano

${ }^{7}$ Los evangelios de Mateo y Lucas aportan vagamente algunas menciones sobre la vida de Jesús, su nacimiento y el comienzo de su vida pública. 
se juega entre dos confines: la Encarnación, y la Parusía y Juicio final. En ese presentismo ya no hay nada nuevo bajo el sol, como se diría en otras culturas. La novedad ya se dio con la Redención realizada por Cristo. En ese sentido se entiende la historia como magistra vitae, como neutralizadora de toda novedad. Si Cicerón había forjado esta fórmula, los cristianos la adoptan, de ahí que la imitación de los comienzos se vuelva una obsesión. En ese sentido, nuevos términos u operativos temporales van surgiendo para acomodarse a Cronos: accomodatio, translatio, reformatio, renovatio, etc., que aparecerán para entender ese presentismo prolongado. Una nueva manera de concebir la historia como maestra de vida siguiendo e imitando el mundo de las primeras comunidades cristianas, bajo el Kairos de la redención.

También se traslada al cristianismo la tradición profética de Daniel, la de translatio imperii, o sucesión de los imperios. Pero, con el paso del tiempo, ¿cómo saber cuáles eran?, o más: ¿eran cuatro o cinco? Además, como se había tomado la contabilidad de los judíos sobre el año en que había sido creado el mundo, con el paso de los siglos el final se vuelve eminente. La caída de Roma en 410 podía indicar el final. En ese contexto, la obra de san Agustín de Hipona La Ciudad de Dios da cuenta de este acontecimiento y propone la explicación de las dos ciudades: la celestial y la terrenal que, encabezada por la Iglesia, llevará a término la historia. Agustín hace uso de todos los elementos e instrumentos operativos de sus predecesores; utiliza las tablas cronológicas anteriores y fija, para muchos siglos, el marco cronológico y el horizonte temporal de la ciudad terrenal, Roma, que llevará a la Jerusalén celestial cuando llegue el final; y, con respecto a la cuestión de los mil años que se mencionan en Apocalipsis 20, Agustín da su veredicto que sería la versión que la Iglesia tomaría como suya. Establece que los mil años indican plenitud del tiempo y advierte, de una vez por todas, que el tiempo le pertenece en exclusiva a Dios, por lo que sólo Él sabe cuándo ocurrirá la Parusía y el Juicio final. De ahí en adelante, Kairos también se carga de otro sentido: se vuelve tiempo de conversión. 
Hasta aquí la contabilidad de Cronos seguía siendo la de la creación del mundo. En el siglo vi (525) Dionisio el Exiguo, nombra al año de la Encarnación el año del Señor, año uno (Anno Domini), sin embargo, en este momento no fue importante, pues será con gran lentitud como se fue imponiendo esta contabilidad que es la propiamente cristiana, ahora sí, con sus dos extremos de inicio y fin. Con sus fronteras ya bien delimitadas queda completa la filosofía, o más bien, la teología de la historia. Cronos se desescatologiza. La primera vez que se encuentra el Anno Domini fue en el siglo viII; en el x se escribe una crónica universal, comenzando con el nacimiento de Cristo; en el XI es más frecuente ver esta datación. La corte papal la utilizaría hasta 1431 (Cfr. p. 126). Cómo se fue acomodando este tiempo cristiano en los siguientes siglos es lo que François Hartog aborda en los capítulos tres y cuatro. Los nuevos operadores temporales mencionados: accomodatio, translatio y renovatio constituyeron maneras como el clero, los humanistas y científicos fueron acomodando, adaptando y comprendiendo sus presentes. La accomodatio pudo dar cuenta del desarrollo y de los cambios en las formas litúrgicas. Es necesario tener en cuenta que las maneras de leer los textos, la lectura tipológica y alegórica eran flexibles. Nunca hubo consensos absolutos, siempre se volvía o se renovaban interpretaciones que retomaban estos operadores temporales. Sobresale la del monje calabrés Joachim de Fiore que, a fines del siglo XII, predice la llegada del Anticristo y piensa que, antes del final, se darían mil años bajo el Espíritu Santo, es decir, una Iglesia de puros, una Iglesia monacal. Estas ideas, consideradas y perseguidas como heréticas, llegaron, muy probablemente, a América, con la primera misión franciscana. Ese momento conjuntaba la visión de translatio imperii que se podía lograr con Carlos I de España -quien podía heredar el Sacro Imperio- con la de renovatio, aquella idea que siempre pugnaba por la renovación de la Iglesia y una vuelta a los orígenes.

Es un hecho que quien llevó la reformatio más lejos fue Martín Lutero, pues con él se clausuró el camino de siglos que 
la Iglesia latina había conducido. La reforma de Lutero pugnaba por alcanzar las fuentes evangélicas a partir de las lenguas en que habían sido escritas. Los humanistas de fines de los siglos xv y XIV buscaron, a su vez, textos en lenguas originales, como una manera de brincarse el latín escolástico y, a partir del griego y del latín clásico, entender y "purificar al cristianismo". Hablaban de un mundo "nuevo", pero construido sobre la "gloriosa cultura romana", de manera que también acudían a la renovatio como fuerza que retomaba el momento inicial de Jesucristo. Todo esto coincidía, en el tiempo, con el momento en que los europeos llegaban a América. Lo cual propiciaría nuevas interpretaciones y respuestas en la segunda mitad del siglo Xvi. La ruptura de la cristiandad europea fue definitiva, pero el tiempo cristiano no se modificó.

Será lentamente como se fue erosionando. Jean Bodin, uno de los primeros en rechazar la ficción de la translatio imperii, la desmontó, pero todavía en el siglo Xvir fue reactivada por el jesuita Antonio Vieira, ahora bajo el rey de Portugal. No obstante, se mantuvo el dominio del tiempo cristiano movilizando sus operativos temporales. Bodin mismo retomó el tiempo cíclico de la Antigüedad para no tocar el Cronos cristiano. Bossuet, por su parte, recuperó la accomodatio, a pesar de que pensadores, hoy casi olvidados, hacían saltar los límites de los seis mil años de antigüedad del mundo. Considerados heréticos en su momento, Joseph Scaliger e Isaac La Peyrère introdujeron la idea de que Adán no había sido el primer hombre, sino había habido otros seres humanos anteriores a él. Si los límites del tiempo cristiano ya se habían hecho estallar (Kairos - Krisis, Juicio Final) no impidió que la pura contabilización de Anno Domini continuara sumando años. A fines del siglo XVII y comienzos del XviII, tanto Bossuet, clérigo católico, como Isaac Newton, puritano antipapista, serían los últimos custodios del tiempo cristiano. Inclusive Newton, el padre de la física moderna, no le movería ni una pizca a este tiempo. Para un cristiano no hay duda de que la vida cristiana es el camino de uno a otro (de Kairos a Krisis). 
A mediados del siglo xviII, en plena Ilustración, el Cronos cristiano empieza a sucumbir. En los últimos dos capítulos de su libro, Hartog trata los estertores del tiempo cristiano ante el avance del capitalismo y, sobre todo, por la Revolución francesa que le da el golpe de gracia. En primer lugar, sus límites se desbordan cuando se comienza a usar el a. de C. y el d. de C. Esto sugiere de inmediato ignorar los seis mil años de la creación. Por otro lado, el tiempo de la Modernidad difiere y aleja la Parusía y el Juicio final. Ahora, a fines del XviII no se puede pensar el acabamiento del mundo. Buffon y Condorcet anticipan el triunfo de un Cronos más que milenario, otorgándole una densidad temporal y espacial (Pascal) enormes; el primero hacia atrás y el segundo hacia delante, postulando, inclusive, la perfectibilidad humana. La ciencia había hecho posible, gracias a la aplicación del cálculo (de probabilidades) avances significativos en todos los ámbitos, lo que hacía ver al futuro promisorio y con confianza.

El siglo XIX, con las ideas de evolución y ciencia triunfantes, hicieron pensar a la sociedad occidental que caminaba, con toda seguridad, hacia un futuro prometedor. El nombre de Darwin, que fue quien llevó el paradigma de la evolución más lejos, acabó por romper las fronteras del tiempo cristiano. La densidad de éste, puesta en jaque desde Buffon, supera ahora por mucho estos cálculos. La doble apertura del tiempo termina por ceder. Tras desvanecerse sus fronteras sólo queda Cronos como contabilización simbólica. El "presentismo apocalíptico" del ya, pero todavía no, desaparece. Cronos ya nada más acumula espesor hacia atrás, y el fin ya no aparece, no, al menos, en los dos siglos que el tiempo moderno duró. La Historia como colectivo singular toma el relevo como vigilante del tiempo, y como juez de y por la historia. Acontecimientos fundadores se vuelven Kairos, como la Revolución francesa, o la de los Estados Unidos. La historia en el siglo xIx toma el papel de Krisis, como juez de la historia.

Resumiendo, hacia fines del siglo xviII y comienzos del xIx emerge el régimen moderno de historicidad, que aleja el campo 
de experiencia del horizonte de expectativas. Es decir, se acelera la percepción temporal, como si la historia fuera más de prisa, del lado de las innovaciones que se producían con gran rapidez después del invento de la máquina de vapor. La aceleración del tiempo pasa significativamente a la metáfora de "locomotora de la historia”, y qué mejor locomotora que la revolución querida por Marx para agilizarla. La "teología de la historia" se convertía en la "religión secular" marxista. Poco después, el tiempo de la Modernidad se reflejó en la escritura de la historia. Las historias nacionales son fruto de este régimen de temporalidad. Había que hacer la historia de la nación, y sabiendo qué se requería del pasado, se escoge de él lo que sirve para hacer más nobles sus orígenes. También iluminaba el objetivo del futuro: la sólida construcción de la nación, las instituciones necesarias y el tipo de identidad a construir. Era una historia teleológica en el sentido más completo de lo que indica esa palabra. La finalidad estaba a los ojos de todos. Ya fuera de la nación, o del régimen de producción: del nacionalismo o de la sociedad del proletariado.

Ernest Renan, ese gran sabio francés que vivió casi todo el siglo xIx, lo visualizó de manera muy positiva en El porvenir de la ciencia, en donde exhibe una fe casi religiosa en ella. Hartog, le dedicó un libro, ${ }^{8}$ percibiéndolo como "personaje doble", que proyecta en la ciencia la fuerza de la convicción religiosa de antaño. Él encarna de manera muy puntual el futurismo de los tiempos modernos.

Este régimen futurista se refleja también en otras historias de Francia del siglo XIX que ven en los acontecimientos $(1830,1848$, la Comuna de París...) el cumplimiento inacabado o inalcanzado. Este inacabamiento no frustra las expectativas. La Revolución francesa se vuelve el pasado del futuro a alcanzar, la Revolución rusa es ejemplo de ello.

${ }^{8}$ François Hartog, La nación, la religión, el porvenir. Tras las huellas de Ernest Renan, México, Ediciones Navarra, 2018. 
En otro sentido, el triunfo del tiempo cristiano se seculariza y sincroniza el reloj mundial. La sincronía del tiempo Cronos se dio con la imposición del meridiano de Greenwich (sobre el de París) a fines del siglo XIx y con la datación del antes de, y después de Cristo como "pivote del tiempo universal". Conquista pírrica, pues en 1905 la teoría de la relatividad demostraba que únicamente se trataba de una convención. Sin embargo, toda esta construcción, nos dice Hartog, había sido mucho más que un ingenuo pasatiempo

El futurismo del progreso tropezó en el siglo xx con las guerras mundiales, genocidios y, más tarde, con toda una reflexión sobre la capacidad de la ciencia, ya no para el progreso de la humanidad, sino en su poder de crear armas tan letales como la bomba atómica. El tiempo moderno ya no se recuperó a pesar del esfuerzo de reconstrucción, de la modernización que impulsó el plan Marshall, en Europa occidental, ni de la promovida del otro lado de la cortina de hierro. La literatura de posguerra mostraba perplejidad, nihilismo y sinsentido. No obstante, tomó tres décadas más en surgir una temporalidad, imperceptible en un principio, que se fue develando en un pasado que seguía presente, un tiempo estancado, que no se desvanecía. Un régimen imprescriptible reflejado en las voces de la memoria (Pierre Nora lo detecta en la década de los ochenta del siglo $\mathrm{xx}$ ), de los testigos de quienes sobrevivieron a Auschwitz, Hiroshima, Nagasaki o al Gulag, que revientan el tiempo del progreso, que es cuestionado y desbancado. De modo que sobreviene un presentismo que no permite olvidar, que tiene "el deber de no olvidar" y que, con los medios masivos de la segunda mitad del xx, acelera todavía más la comunicabilidad. El desencanto del paraíso socialista, o del sueńo americano, de fines del siglo pasado, fortalece ese presentismo que quiere conservar todo y que es el que Hartog diagnosticó en Regímenes de historicidad con sus "síntomas": patrimonio, conmemoración, memoria e identidad. Ahora, en Cronos se concentra en un nuevo orden del tiempo: el Antropoceno. En diálogo con los estudios de Dipesh 
Chakrabarty nos muestra que se dan estratos del tiempo inconmensurables: la edad de la tierra no tiene nada que ver con las épocas de la historia humana.

Antropoceno, categoría surgida en el año 2000, ya no desaparece (Cfr. p. 301). ${ }^{9}$ No se sabe, a ciencia cierta, si los geólogos la aceptan bajo el presupuesto de que los desechos humanos quedarán como una huella de la destrucción que el ser humano le imprime a la vida de especies que desaparecen. En la profunda temporalidad de millones de años contemplada por los geólogos, la brevedad de la presencia humana está por quedar marcada en las mismas capas geológicas, y es en este sentido que Antropoceno puede consolidarse y, a la vez, relativizarse con respecto a la vida del planeta que sin duda superará el paso humano. Lo que es cierto, es que el uso de la palabra "catástrofe" es continuo y en el mundo occidental remueve el espectro del Apocalipsis. El tiempo de Occidente viene de muy atrás y ahora lo deja. Vivir es hacer la experiencia a través del tiempo. Pero ésa es sólo una forma de ver el tiempo. Cronos va más allá de eso. Antropoceno, parece que llegó para quedarse; es un tiempo inmensamente viejo y muy nuevo a la vez: el tiempo de la tierra que ha venido a trastornar nuestra economía del tiempo. Sin embargo, oculta disimetrías evidentes que se tienen que evidenciar para poder tomar decisiones, para entender el cambio climático y poder plantearlo, no con la simplicidad de relaciones de poder, ni con el afán de culpar más a unos que a otros, sino, con los geólogos, ver el espesor de sus tiempos, con relación al presentismo catastrofista de nuestro presentismo (Cfr. pp. 294 ss.). ${ }^{10}$

Este resumen del argumento del libro de Hartog no puede dar cuenta de todos los matices y lecturas que están detrás ni tam-

\footnotetext{
${ }^{9}$ Hartog nos dice que la palabra Antropoceno fue introducida por Paul Crutzen en el año 2000.

${ }^{10}$ Acerca de la disimetría de temporalidades, Hartog previene reflexionar sobre el presentismo y la temporalidad de miles de millones de años, que son los tiempos que los geólogos manejan.
} 
poco del cuidado que el autor tiene por escoger las palabras para explicar, siempre desde la historia, el tiempo con que Occidente se ha enfrentado al tiempo. François Hartog lleva décadas pensando y dando vueltas a su reflexión sobre el tiempo. Desde aquel ensayo pionero en la década de los ochenta del siglo xx, cuando, interesado en la antropología, descubría lo simultáneo de lo no simultáneo a partir de Marshall Sahlins. Otros tiempos otras historias. Su reflexión siempre ha girado en torno a la historia y al tiempo. Su obra refleja años de investigación en la que siempre, dando un paso más allá del anterior, a veces de lado, o regresando a diferentes pasados, ha ido concretando ideas y seleccionando palabras, puesto que tiene la decisión de escribir como historiador, sin valerse de conceptos filosóficos que, como he dicho, no implica que trabaje sin teoría. Siempre ha leído filosofía, teoría de la historia y mucha literatura que le vuelve muy sensible a aquellas palabras de grandes escritores que perciben lo que todavía no es. Él lo reelabora. Durante años enteros en su seminario de la École des hautes études en sciences sociales enseña a leer cómo lee un historiador. De la literatura profética hebrea a san Agustín, de periodos antiguos a modernos, de la historiografía renacentista a la Revolución francesa. Textos y textos. Siempre atento a las marcas de enunciación, comparando para "poder ver más allä", sin encasillarse en temas o periodos.

$\mathrm{Su}$ punto de partida siempre es el presente. Nunca ha pretendido otra cosa que ofrecer una mayor inteligibilidad sobre nuestro tiempo, nuestra sociedad. Sin intentar nunca decir la última palabra sobre nada. Su profunda conciencia de historicidad aspira a ofrecer una mejor inteligibilidad del presente que ayude a orientarnos en nuestro presente. Es ahí donde puede ayudarnos a concientizar sobre los demonios que otros sueltan ante cada catástrofe anticipando el fin. Sólo Occidente puede contemplar Apocalipsis ante toda catástrofe.

Ojalá veamos pronto traducido esta obra que enriquecerá la escritura de la historia, pero no nada más a ésta; el libro iluminará 
toda disciplina y agencia para ver más allá de este presente que sólo devela incertidumbre y miedo. Hartog cierra su libro con una posdata escrita en abril de 2020. Ese mes Cronos habría salido a la luz. Se postergó ante la covid y apareció en octubre. Con este final, su reflexión continúa. Ya pensando en lo que prefiguran las palabras: confinamiento, krisis, encierro, Hartog advierte que, en Occidente, y ahí sin más, retorna el espectro apocalíptico. 糘 